\title{
In Vitro Effect of Methanolic Extract of Argemone mexicana against Trichomonas vaginalis
}

\author{
Joel Horacio Elizondo-Luevano', Julia Verde-Star', Azucena González-Horta', Rocío Castro-Ríos², \\ Magda Elizabeth Hernández-García ${ }^{3, *}$, Abelardo Chávez-Montes ${ }^{1, *}$
}

${ }^{1}$ Department of Chemistry, College of Biological Sciences, Autonomous University of Nuevo León, Nuevo León 66455, México; ${ }^{2}$ Department of Analytic Chemistry, College of Medicine, Autonomous University of Nuevo León, Nuevo León 64460, México; ${ }^{3}$ Northeast Biomedical Research Center, Instituto Mexicano del Seguro Social, Nuevo León 64720, México

\begin{abstract}
Infections caused by Trichomonas vaginalis in humans are one of the main public health problems caused by sexually transmitted diseases. Objective of this study was to evaluate potential biological activity of the medicinal plant $A r-$ gemone mexicana (Mexican poppy) on $T$. vaginalis. Methanolic extracts of the stems and leaves of $A$. mexicana, and different fractions were prepared with solvents of different polarities. The extracts and functional groups were detected containing sterols, triterpenes, quinones, flavonoids and, alkaloids. Extracts from both the stems and leaves of $A$. mexicana inhibited the growth of $T$. vaginalis with half-maximal inhibitory concentration value of 70.6 and $67.2 \mu \mathrm{g} / \mathrm{ml}$, respectively. In the active fractions, the most abundant compounds were berberine and jatrorrhizine, with presumed antiparasitic activity.
\end{abstract}

Key words: Argemone mexicana, Trichomonas vaginalis, trichomoniasis, alkaloids

\section{INTRODUCTION}

Trichomoniasis is a sexually transmitted disease caused by the flagellated protozoan Trichomonas vaginalis (Donné, 1836) that is more frequent than gonorrhea, syphilis or chlamydia; furthermore, it is considered the most common nonviral sexually transmitted disease in the world, the highest incidence occurs in women between 16 and 35 years of age, and the overall prevalence has been estimated at $8.1 \%$ for women and $1.0 \%$ for men [1]. Due to the increased prevalence of this disease and the emergence of strains resistant to the drug of choice, metronidazole, the search for alternative active principles is essential for the effective control of this disease [2]. The World Health Organization estimated that there were 276.4 million cases of trichomoniasis in 2013, and $90 \%$ of these infections occurred among people living under precarious conditions with limited resources [3].

Natural products, especially plants, are an important source of metabolites with diverse biological properties that can be

- Received 9 October 2019, revised 9 March 2020, accepted 13 March 2020.

* Corresponding authors

(abelardo.chavezmn@uanl.edu.mx; magda.hernandez@imss.gob.mx)

(c) 2020, Korean Society for Parasitology and Tropical Medicine

This is an Open Access article distributed under the terms of the Creative Commons Attribution Non-Commercial License (https://creativecommons.org/licenses/by-nc/4.0) which permits unrestricted non-commercial use, distribution, and reproduction in any

medium, provided the original work is properly cited. used as active principles for the treatment of diseases, and the therapeutic use of medicinal plants is the fundamental basis for the discovery and development of new active principles, as such plants contain metabolites with diverse biological properties [4]. Popular knowledge of medicinal plant use is a powerful tool in the search for new active principles and, the WHO estimates that between $65 \%$ and $80 \%$ of the population in developing countries depends on traditional medicine [5]. In Mexico, plants are an abundant and accessible resource, and their use in traditional medicine dates back to the pre-hispanic era [6].

Argemone mexicana (Mexican poppy) is a plant that is widely distributed in many tropical and subtropical countries, and it is commonly found on the edges of roads or in vacant lots, this plant, also known as Mexican poppy, is an annual erect thorny herb of approximately $1 \mathrm{~m}$ in height with broad leaves at the base (usually measuring 5 to $11 \mathrm{~cm}$ long) with green and white spots on their surfaces, and the stem is prominently lobed-sinuous and thorny [7]. The presence of various types of chemical constituents has been reported in this plant, with alkaloids being the most abundant [8]. In traditional medicine, different parts of this plant are used to treat chronic skin diseases and the flowers have expectorant properties and have been used in the treatment of cough [9]. The seeds have a laxative effect, and the latex is used against conjunctivitis, the seed 
oil is used as a remedy for asthma, ulcers, dysentery and other intestinal conditions $[10,11]$. Furthermore, various parts of $A$. mexicana plants have been shown to have activity against malaria, leishmaniasis, and trypanosomiasis diseases caused by Plasmodium falciparum, Leishmania donovani, and Trypanosoma brucei rhodesiense, respectively [12-14].

Given the above background information and the traditional use of A. mexicana as a medicinal plant, the main objective of this study was to evaluate the potential biological activity of $A$. mexicana against the viability of $T$. vaginalis. Specifically, the activities of methanolic extracts from A. mexicana stems and leaves, as well as their fractions, were evaluated against T. vaginalis.

\section{MATERIALS AND METHODS}

\section{Plant and microbiological material}

The stems and leaves of A. mexicana were collected in February 2018 in the city of San Nicolás de los Garza [25 $24^{\circ} 15.3^{\prime \prime} \mathrm{N}$ $\left.100^{\circ} 19^{\prime} 00.3^{\prime \prime} \mathrm{W}\right]$ in the state of Nuevo León, Mexico. The plant was taxonomically identified at the Laboratory of Botany, College of Biological Sciences, Autonomous University of Nuevo León, under registration number 029128. T. vaginalis strain GT15 IMSS:0989 was provided by the Northeast Biomedical Research Center of the Instituto Mexicano del Seguro Social (IMSS).

\section{Extraction}

To obtain the methanolic extracts of A. mexicana, the stems and leaves were dried at room temperature and subjected to extraction via maceration. A $100 \mathrm{~g}$ portion was ground into a fine powder that was then used for successive extractions $(5 \times 250 \mathrm{ml})$ with absolute methanol (Sigma Chemical Co. St. Louis, Missouri, USA) at room temperature in an amber flask on an orbital shaker (LAB-LINE, 3508, LAB-LINE Instruments, Inc. Melrose Park, Illinois, USA) with stirring (100 rpm) and solvent replacement every $24 \mathrm{hr}$. The extract was filtered through Whatman filter paper No. 1 and concentrated under reduced pressure at $45^{\circ} \mathrm{C}$ with the aid of a rotary evaporator (Heidolph ${ }^{\circledR}$ Rotary Evaporator, Laborota 4010). The residual solvent was evaporated at room temperature, and the obtained solid extracts were weighed to calculate the percent yield. The extracts were referred to as the AmexS (stem) and AmexL (leaf) extracts, and they were stored in the dark at $4^{\circ} \mathrm{C}$ until subsequent use. To fractionate the AmexS and AmexL extracts, the solid extract was serially partitioned using solvents of different polarities. The total crude solid extract was dissolved in $100 \mathrm{ml}$ of hexane via magnetic stirring for $10 \mathrm{~min}$ at $25^{\circ} \mathrm{C}$. The solution was filtered through Whatman No. 1 paper, and the obtained solid residue was subjected to the same treatment with an additional $50 \mathrm{ml}$ portion of hexane. The two hexane solutions were then mixed (fraction 1). The residue was extracted with three $50 \mathrm{ml}$ portions of $\mathrm{CHCl}_{3}$ (fraction 2), which were then also filtered through Whatman paper, and the solid residue was extracted with absolute $\mathrm{MeOH}(4 \times 50 \mathrm{ml})$ and filtered through Whatman No. 1 (fraction 3). Next, $100 \mathrm{ml}$ of methanol was added to the resulting insoluble solid, and the mixture was heated $\left(60^{\circ} \mathrm{C}\right)$ for $5 \mathrm{~min}$ with stirring and then filtered (fraction 4). Last, the remaining solid was solubilized in $30 \mathrm{ml}$ of distilled water (fraction 5). The solution was filtered, frozen at $-20^{\circ} \mathrm{C}$ and lyophilized at $-50^{\circ} \mathrm{C}$ and $0.2 \mathrm{mBar}$ (FreeZone 2.5 Liter Benchtop Freeze Dryer, LABCONCO, Missouri, USA). This procedure was applied to stems and leaves separately, and all of the solvents were analytical grade. The following equation was used to calculate the yield for each extraction ( $\mathrm{WE}=$ weight of the extract obtained and $\mathrm{WI}=$ initial weight of the plant material):

$$
\text { Yield }\left(\% \frac{\mathrm{w}}{\mathrm{w}}\right)=\frac{\mathrm{WE}}{\mathrm{WI}} \times 100
$$

\section{Phytochemical analysis}

Various selective qualitative techniques were used for the basic phytochemical analysis of the extracts: 2,4-dinitrophenylhydrazine (carbonyl groups), anthrone (carbohydrates), Baljet (sesquiterpene lactones and coumarins), sodium bicarbonate (carboxyl groups), ferric chloride (phenols and tannins), Dragendorff (alkaloids), Liebermann-Burchard (sterols and triterpenes), potassium permanganate (double bonds), Shinoda (flavonoids), sodium hydroxide (coumarins), Bornträger (quinones) and the saponins test [15].

\section{Growth kinetics of $T$. vaginalis}

Growth curves were generated in triplicate by recording the growth for $120 \mathrm{hr}$ after inoculation of 100,000 T. vaginalis GT15 trophozoites into $5 \mathrm{ml}$ of TYI-S-33 medium supplemented with $10 \%$ bovine serum in $13 \times 100 \mathrm{~mm}$ screw-cap tubes. The trophozoites were incubated at $37^{\circ} \mathrm{C}$ for $120 \mathrm{hr}$, and the number of trophozoites was determined every $24 \mathrm{hr}$ and their growth parameters in the medium were evaluated. Linear regression was used to obtain the growth parameters, generation time and protozoan doubling time. The generation time 
was determined via the following equation:

$$
\mathrm{G}=\frac{\mathrm{t}}{3.3} \log \frac{b}{B}
$$

$\mathrm{G}=$ generation time, $\mathrm{t}=$ time interval of the exponential phase, $\mathrm{B}=$ number of organisms at the beginning of the time interval, $b=$ number of organisms at the end of the time interval. To determine the doubling time (dt), the following equation was used: $\mathrm{dt}=0.693 \mathrm{G}$.

\section{Activity of the extracts against $T$. vaginalis}

The activity of the methanolic extracts against $T$. vaginalis was evaluated using a microassay technique [16]. In an amber bottle, a concentrated solution of the crude methanolic extract (1 $\mathrm{mg} / \mathrm{ml}$ ) was prepared in $5 \% \mathrm{w} / \mathrm{v}$ dimethylsulfoxide (DMSO). This solution was sterilized by passing it through a $0.2 \mu \mathrm{m}$ pore size nylon membrane filter (Merck Millipore, KGaA, Darmstadt, Germany), and it was stored at $4^{\circ} \mathrm{C}$ until use. Serial dilutions were produced by adding $500 \mu \mathrm{l}$ of sterile deionized water to $500 \mu \mathrm{l}$ of the concentrated solution. The concentrations of the working solutions were 15.6, 31.3, 62.5, 125, 250, 500, and $1,000 \mu \mathrm{g} / \mathrm{mL} .1 \times 10^{5}$ T. vaginalis in logarithmic phase were inoculated into $1 \mathrm{ml}$ aliquots of TYI-S-33 medium in culture tubes (Bellco Biotechnology, BellcoGlass Inc., Vineland, New Jersey, USA), and $50 \mu \mathrm{l}$ of the working solutions was added to each tube. The tubes were then incubated at $37^{\circ} \mathrm{C}$ for $24 \mathrm{hr}$ Metronidazole $(0.1 \mu \mathrm{g} / \mathrm{ml})$ was used as a positive control, $5 \%$ DMSO was used as a negative control and TYI-S-33 culture medium is used as a blank control [17]. After the incubation period, the tubes containing the treated cultures were cooled to $4^{\circ} \mathrm{C}$ in ice water for $20 \mathrm{~min}$, and the number of trophozoites per $\mathrm{ml}$ in each tube was counted with a hemocytometer (Neubauer, Hausser Scientific, Horsham, Pennsylvania, USA). For counting, a 1:10 dilution in formalin was first performed to fix the trophozoites. The results were expressed as the percentage of growth inhibition in the treated cultures compared to those of the untreated controls. The half-maximal inhibitory concentrations $\left(\mathrm{IC}_{50}\right)$ were determined via the Probit statistical test. All assays were performed in triplicate.

\section{Analysis via liquid chromatography and mass spectrometry}

The AmexS and AmexL crude extracts, as well as the active fractions were analyzed via a high-performance liquid chromatography-diode array detector (HPLC-DAD). Briefly, $15 \mathrm{mg}$ units of the dry fractions were dissolved in a $1 \mathrm{ml}$ methanol mixture and then filtered through a $0.2 \mathrm{~mm}$ pore size nylon membrane (Millipore Millex ${ }^{\circledR}$ ). For the analysis, an Alliance 2695 liquid chromatograph (Waters) equipped with an in-line degasser, quaternary pump, autosampler, column temperature control module and, diode array detector was used. The separation was carried out in a Kinetex PFP column $(50 \times 2.1 \mathrm{~mm}$; Phenomenex, Torrance, California, USA) with a mixture of an aqueous solution of formic acid (1\%) and methanol as the mobile phase. The gradient program started with 30\% methanol, which was maintained for $2 \mathrm{~min}$, followed by a linear increase to $100 \%$ over $5 \mathrm{~min}$. This concentration was maintained for 1 $\mathrm{min}$ and then returned to the initial conditions over $2 \mathrm{~min}$. The reconditioning time between analyses was $10 \mathrm{~min}$. The mobile phase flow rate was $400 \mu \mathrm{l} / \mathrm{min}$, the column was maintained at $50^{\circ} \mathrm{C}$ and the injection volume was $0.5 \mu \mathrm{l}$. To confirm the identities of the components identified in the active fractions, mass spectrometry analysis was performed via direct infusion using an LCQ Fleet (Thermo Scientific) mass spectrometer equipped with an electrospray ionization source and an ion trap analyzer. In the ionization source, nitrogen was used as the sheath gas at a flow rate of 30 units. Working in positive mode, the voltage of the electrospray capillary was set to $5 \mathrm{kV}$ and the voltage of the desolvation capillary set to $43 \mathrm{~V}$ at $275^{\circ} \mathrm{C}$. The lens tube voltage was maintained at $75 \mathrm{~V}$. Data acquisition was performed in fullscan mode over a mass-to-charge ratio $(\mathrm{m} / \mathrm{z})$ range of 100 to 1,000 . In mass/mass experiments for the most intense ions, the collision-induced dissociation (CID) mode was used, and the normalized collision energy was adjusted to obtain adequate fragmentation with an insulation width of $1 \mathrm{~m} / \mathrm{z}$, an activation Q of 0.3 and an activation time of $30 \mathrm{~ms}$.

\section{Cytotoxicity assessment for methanolic extract by hemolysis test}

Cytotoxicity was evaluated by monitoring the hemolysis of an erythrocyte suspension. Human blood was obtained from healthy donors, and the blood was mixed with EDTA $(1.5 \mathrm{mg} /$ $\mathrm{ml}$ of blood) and separated via centrifugation at 1,000 rpm for $5 \mathrm{~min}$ at $37^{\circ} \mathrm{C}$. The cell pellet was washed four times with phosphate-buffered solution (PBS pH 7.4, $10 \mathrm{mM}$ ) and the supernatants were discarded. The erythrocytes were subsequently used to prepare a red blood cell suspension for $5 \% \mathrm{v} / \mathrm{v}$ assays in PBS. To evaluate the cytotoxicity of the extracts against the erythrocytes, aliquots of the previously prepared red blood cell suspension were incubated with different concentrations of the extracts for $30 \mathrm{~min}$ at $37^{\circ} \mathrm{C}$ protected from 
light. A solution of untreated erythrocytes (Abs Ctrl-) was used as a negative control. For the positive control, sterile distilled water was added to untreated erythrocytes to induce osmotic hemolysis (Abs Ctrl+) [18]. After incubation, spectrophotometric readings were taken at $540 \mathrm{~nm}$, the maximum absorption wavelength of the hemoglobin released in the supernatant, using a microplate reader (EPOCH ${ }^{\mathrm{TM}}$ Microplate Spectrophotometer; BioTek Instruments, Winooski, Vermont, USA). The readings were recorded as the absorbance of the treated samples at each concentration given in parts per million (Abs Tx) [19]. These values were used to calculate the percentage of hemolysis using the following Equation:

$$
\% \text { Hemolysis }=\left[\frac{(\text { Abs Tx })-(\text { Abs Ctrl }-)}{(\text { Abs Ctrl }+)-(\text { Abs Ctrl })}\right] \times 100
$$

\section{Statistical analysis}

One-way analysis of variance (One-way ANOVA) was used to evaluate the performance of the extracts at different concentrations, and the Tukey test (Post-Hoc) was used for multiple comparison of means $(P \leq 0.05)$. In addition, the Probit test was used to determine the concentration required for $50 \%$ growth inhibition $\left(\mathrm{IC}_{50}\right.$ ) with a confidence interval of $95 \%$ using SPSS version 24.0 (SPSS. Inc., Chicago, Illinois, USA). All assays were performed in triplicate.

\section{RESULTS}

\section{Compounds in extract fractions}

The present study evaluated the trichomonacidal activity of the methanolic extracts of A. mexicana stems and leaves, the fractions of these extracts obtained via partitioning with solvents of different polarities. The yields of the maceration-based extractions were $10.0 \%$ and $12.7 \%$ for the dry stems and leaves, respectively. The results of the basic phytochemical analysis of the crude extracts are presented in Table 1. Unsaturates, quinones, sterols, triterpenes, saponins, flavonoids, carbohydrates, and alkaloids were detected in both the AmexS and AmexL extracts. The results suggest that, the plant showed both presence and absence of various compounds. Then, the crude extracts were analyzed via HPLC-DAD. As shown in Fig. 1A, B, they presented similar chromatographic profiles. In both extracts, signals with retention times and absorption spectra were very similar to that of the alkaloid berberine (Fig. 1C).
Table 1. Phytochemical analysis on crude extracts of Argemone mexicana stems and leaves

\begin{tabular}{lcc}
\hline Chemical test & AmexS & AmexL \\
\hline Unsaturates & +++ & + \\
Carbonyl groups & - & - \\
Coumarins & - & - \\
Sesquiterpene lactones & - & - \\
Quinones & + & ++ \\
Triterpenes - sterols & + & + \\
Carboxyl group & - & - \\
Phenolic groups & + & ++ \\
Saponins & + & + \\
Flavonoids & + & ++ \\
Carbohydrates & +++ & + \\
Alkaloids & +++ & +++ \\
\hline
\end{tabular}

The preliminary phytochemicals were analyzed in order to detect presence or absence of some important phyto-compounds. The results in the phytochemical tests are presented as negative - or presence + , high presence ++ and very high presence +++. The plant showed both presence and absence of various compounds.

\section{Growth kinetics of $T$. vaginalis}

To evaluate the activity of the extract, it was necessary to first determine the time required for the T. vaginalis cultures to reach the logarithmic growth phase, that is, the optimum growth point that indicates the greatest number of trophozoites. To this end, a growth kinetics analysis was performed (Fig. 2). We observe that T. vaginalis have a generation time of $5.8 \mathrm{hr}$ and a doubling time of $4.0 \mathrm{hr}$, so its exponential phase is at $48 \mathrm{hr}$. With these results we establish the incubation time parameters for the parasite before starting with the biological tests.

\section{Activity of extracts against $T$. vaginalis}

Table 2 shows the results obtained from in vitro assays of the activities of the methanolic crude extracts of the stems (AmexS) and leaves (AmexL) against T. vaginalis growth. Both extracts could inhibit trophozoite growth, and there was a clear dose-response relationship as the percentage of inhibition decreased with decreasing extract concentration. For both AmexS and AmexL, total inhibition was achieved at a concentration of $1,000 \mu \mathrm{g} / \mathrm{ml}$, and at $500 \mu \mathrm{g} / \mathrm{ml}$, the inhibition shown by both extracts was greater than $97 \%$; furthermore, as the doses decreased, the viability increased. The positive control $(0.124 \mu \mathrm{g} / \mathrm{ml}$ metronidazole) showed $100 \%$ inhibition, while the negative control and the Blank control showed almost no inhibition (2.0\% and $1.0 \%$, respectively). The activities of the AmexS and AmexL extracts were compared via ANOVA $(P>0.05)$. The Tukey test was used for multiple com- 


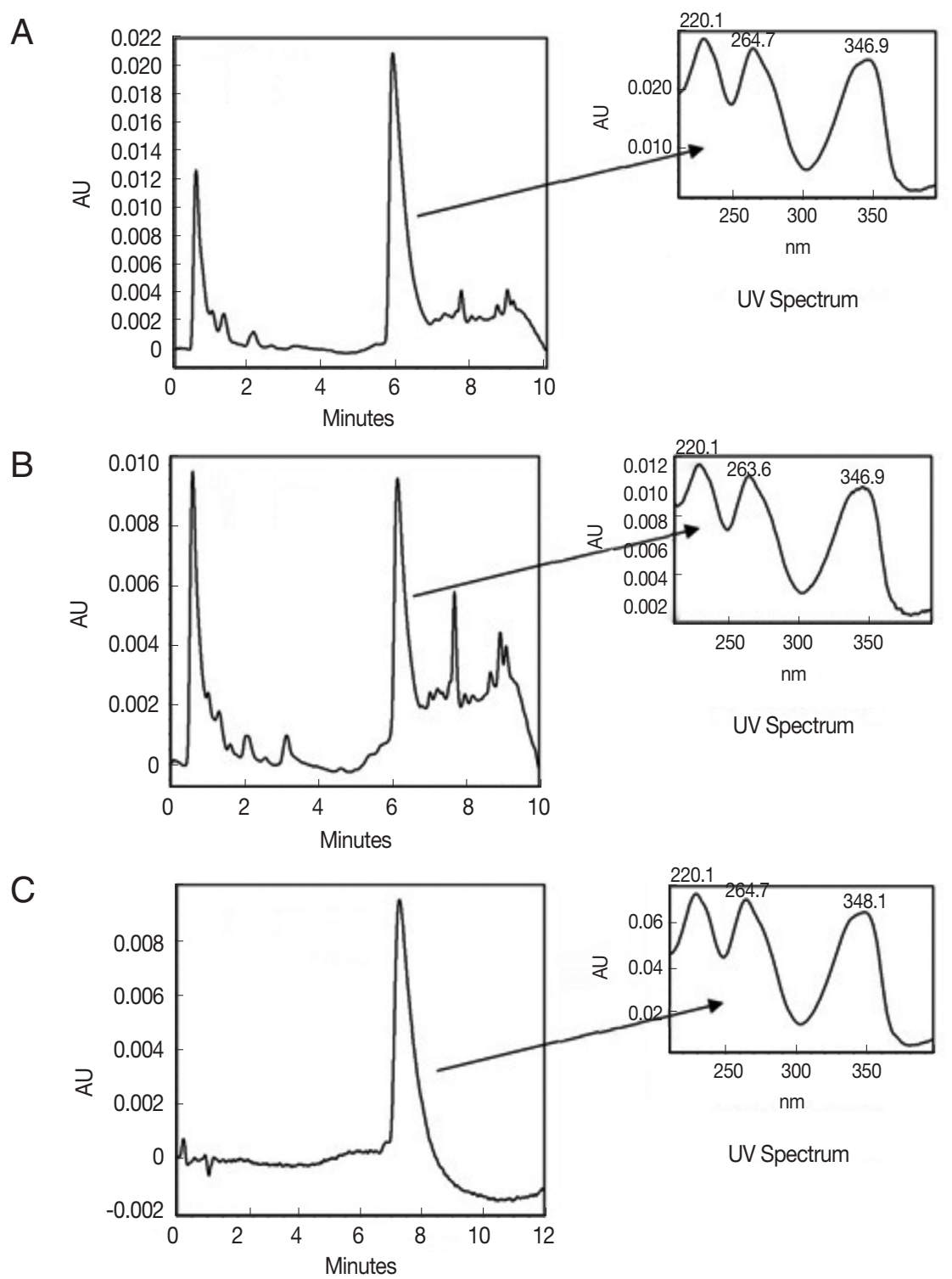

Fig. 1. HPLC-DAD chromatograms for AmexS (A), AmexL (B) crude extracts and berberine (C) solutions (15 mg/ml).

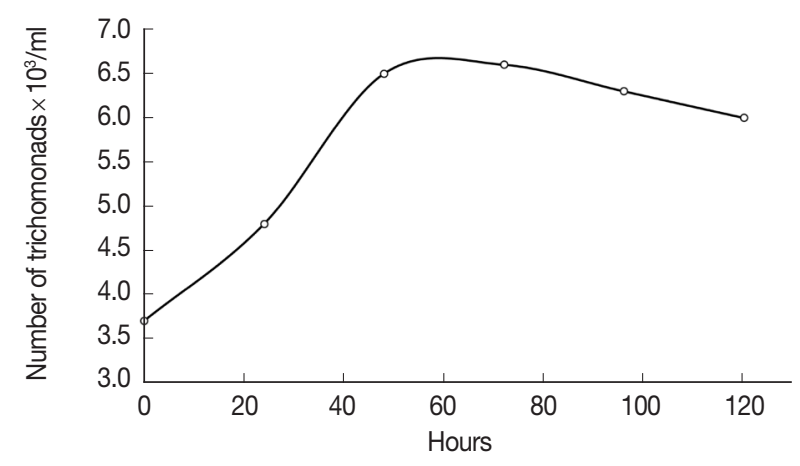

Fig. 2. Growth kinetics of Trichomonas vaginalis in TYI-S-33 medium. Each point is mean of 3 independent counts. parison of the means of the inhibitory effects of the AmexS and AmexL extracts (Table 2).

\section{Inhibitory concentrations}

The $\mathrm{IC}_{50}$ values of the extracts against T. vaginalis, estimated via the Probit method, are shown in Table 3. The IC $\mathrm{C}_{50}$ values of both the AmexS and AmexL extracts were less than $100 \mu \mathrm{g} / \mathrm{ml}$. The $\mathrm{IC}_{50}$ determination against $T$. vaginalis showed that the stem and leaf methanolic extracts had an $\mathrm{IC}_{50}$ of 70.8 and 67.2 $\mu \mathrm{g} / \mathrm{ml}$, respectively, an $\mathrm{IC}_{50}$ analysis was also performed for the first-choice drug (metronidazole), and for the metabolite most 
Table 2. Percentage of inhibition of Trichomonas vaginalis growth

\begin{tabular}{|c|c|c|c|c|c|c|c|}
\hline \multirow{2}{*}{ Extract } & \multicolumn{7}{|c|}{ Concentration ( $\mu \mathrm{g} / \mathrm{ml})$} \\
\hline & 15.63 & 31.25 & 62.5 & 125 & 250 & 500 & 1,000 \\
\hline AmexS & $14.7 \pm 1.2$ & $25.3 \pm 1.2$ & $38.7 \pm 0.4$ & $64.4 \pm 0.6$ & $83.4 \pm 2.0$ & $97.4 \pm 0.1$ & $100.0 \pm 0.0$ \\
\hline AmexL & $18.0 \pm 1.1$ & $29.6 \pm 1.6$ & $40.4 \pm 0.8$ & $70.1 \pm 0.3$ & $84.2 \pm 1.9$ & $98.1 \pm 0.0$ & $100.0 \pm 0.0$ \\
\hline
\end{tabular}

Evaluation of $T$. vaginalis viability in the presence of different extract concentrations. The values are shown as the mean of the percent inhibition \pm SD. Means followed by the same letter are not significantly different based on the Tukey test for multiple comparisons of means $(P<0.05)$. All assays were performed in triplicate.

Table 3. Mean half maximal inhibitory concentrations ( $\left.\mathrm{IC}_{50}\right)$ against Trichomonas vaginalis determined by the Probit test

\begin{tabular}{lc}
\hline Treatment & $I_{50}(\mu \mathrm{g} / \mathrm{ml})$ \\
\hline AmexS & $70.8(63.6-86.2)$ \\
AmexL & $67.2(61.9-74.7)$ \\
Berberine & $40.7(35.5-47.8)$ \\
Metronidazole & $0.1(0.1-0.2)$ \\
\hline
\end{tabular}

The values are shown as the mean \pm SD. Confidence interval 95\%. Berberine: Main metabolite of $A$. mexicana. Metronidazole: Reference drug for the treatment of $T$. vaginalis. All assays were performed in triplicate.

A

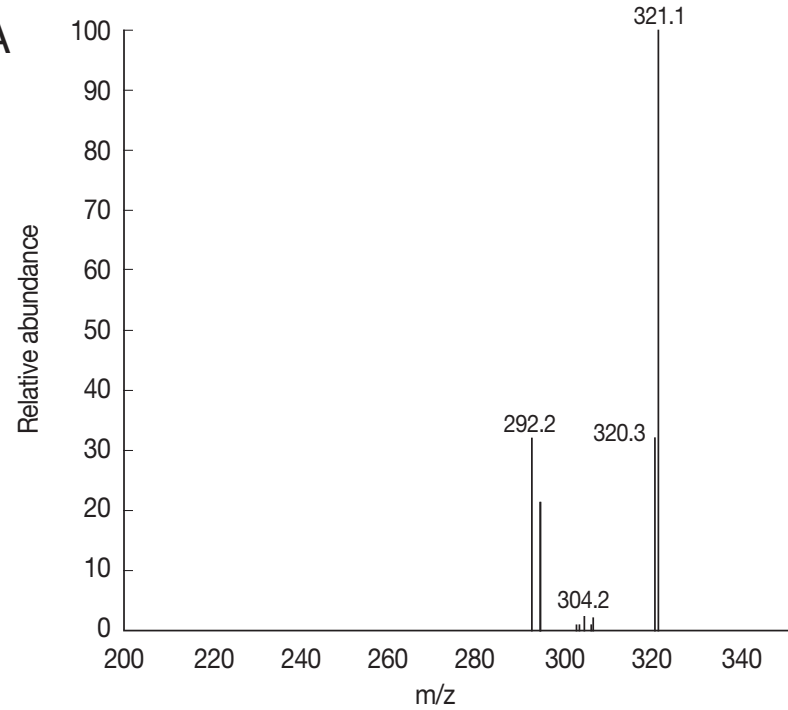

Table 4. Lethality percentage of fractions of the AmexS and AmexL extracts against Trichomonas vaginalis at $125 \mu \mathrm{g} / \mathrm{ml}$

\begin{tabular}{lcc}
\hline Fraction & AmexS & AmexL \\
\hline 1 & ND & $50.4 \pm 1.9$ \\
2 & $51.1 \pm 0.5$ & $53.2 \pm 2.0$ \\
3 & $73.0 \pm 0.1$ & $79.2 \pm 0.2$ \\
4 & ND & $55.2 \pm 0.3$ \\
5 & ND & ND
\end{tabular}

Data expressed as \% lethality. ND: not determined because it did not reach $50 \%$ inhibition. The values are expressed as the mean \pm SD $(P<0.05)$. All assays were performed in triplicate.

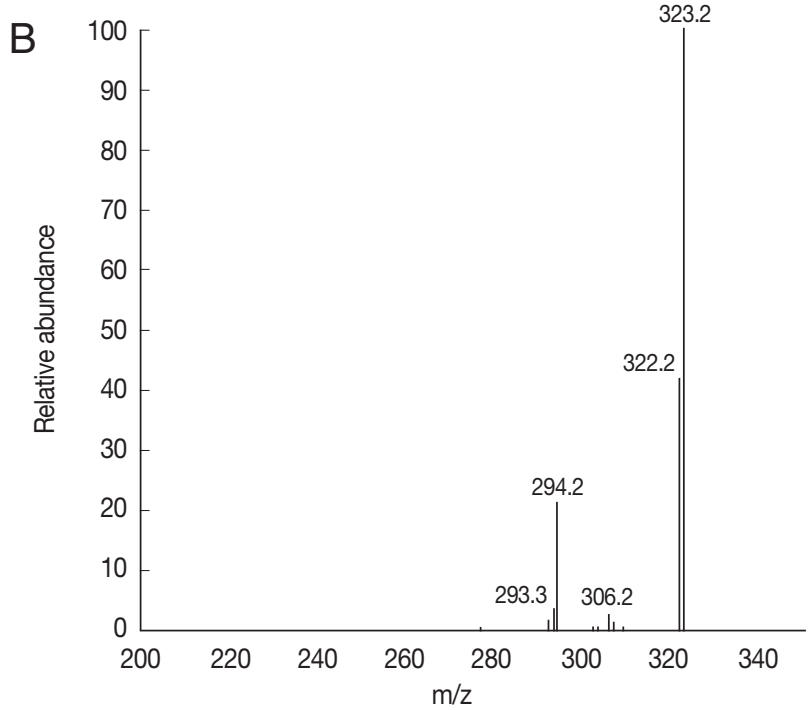

Fig. 3. Direct infusion-electrospray ionization-ion-trap MS2 full scan product. lon mass spectra of $[\mathrm{M}]+$ ions of $(\mathrm{A})$ berberine (m/z 336) and (B) jatrorrhizine (m/z 338) obtained from the AmexL3 fraction.

widely reported in this plant (berberine), metronidazole showed an $\mathrm{IC}_{50}$ of $0.1 \mu \mathrm{g} / \mathrm{ml}$ and berberine of $40.7 \mu \mathrm{g} / \mathrm{ml}$. IC $\mathrm{I}_{50}$ was determined with total crude extract without fractionation and it can be seen that berberine presented a better result than raw extracts. Once the trichomonacidal activities of the extracts were determined, the extracts were partially purified via fractionation based on their solubility in 5 solvents with various polarities. These fractions were numbered, and their lethality against T. vaginalis was evaluated at a concentration of $125 \mu \mathrm{g} /$ $\mathrm{ml}$. The most efficient fractions from both the AmexS and AmexL extracts were the methanolic partitions, which showed lethality percentages of $73.0 \%$ and $79.2 \%$, respectively. Therefore, of all the fractions, AmexL3 was classified as an active fraction (Table 4).

To characterize the active fraction (AmexL3), it was analyzed by tandem mass spectrometry (MS/MS). Among the signals 


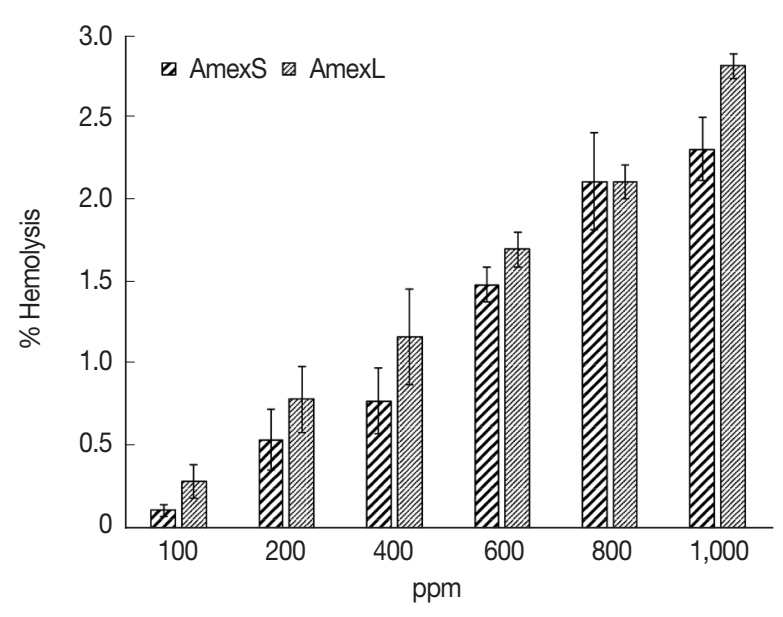

Fig. 4. Hemolytic cytotoxicity of AmexS and AmexL extracts. The results in the columns are shown as the percentage of hemolysis. Values are shown as mean \pm SD. All assays were performed in triplicate.

with the highest intensities, the ions at $\mathrm{m} / \mathrm{z} 336$ and 338 were attributed to berberine (Fig. 3A) and jatrorrhizine (Fig. 3B). All the data for compounds were consistent with the reported values for berberine and jatrorrhizine.

\section{Least cytotoxicity of the crude extracts}

Considering the potential use of the extracts, it was decided to evaluate the cytotoxicity of the crude A. mexicana stem and leaf extracts via a human erythrocyte hemolysis test. It was observed that none of the extracts were significantly cytotoxic, as even at the highest concentration tested $(1,000 \mu \mathrm{g} / \mathrm{ml})$. It was found that the stem and leaf extracts resulted in hemolysis of $2.3 \%$ and $2.8 \% \mathrm{RBCs}$, respectively. At the lowest concentrations $(100 \mu \mathrm{g} / \mathrm{ml})$, the percentages erythrocyte hemolysis of the stem and leaf extracts were $0.1 \%$ and $0.3 \%$, respectively (Fig. 4). The negative control did not show detectable hemolysis, and the positive control (distilled water) showed $100 \%$ hemolysis.

\section{DISCUSSION}

In the present investigation, extracts of A. mexicana L. (Papaveraceae) stems and leaves and their fractions obtained by partitioning with solvents of different polarities were evaluated for determination of their activity against T. vaginalis. Extractions were carried out by maceration with methanol, the percentages of crude extract yield are similar to a previous study that worked with extract of the entire plant, which obtained a yield of $10.7 \%$ [20]. The results of the basic phytochemical analysis (Table 1) are consistent with those of a previous study that alkaloids were the predominant compounds [5]. Terpenoids, flavonoids, alkaloids, terpenes, long-chain aliphatic compounds and a few aromatics are also detected as constituents of this plant. It should be noted that the chemical composition of the plant may differ depending on which parts analyzed, the harvesting time and the geographical area [21].

The crude extracts were analyzed by HPLC-DAD, their chromatographic profiles with signals, retention times and absorption spectra were very similar to that of the alkaloid berberine. These results are consistent with those of other studies that detected the presence of this alkaloid in the leaves of A. mexicana by analyses of methanolic extracts $[13,22]$. Also, previously performed phytochemical tests revealed the presence of several alkaloids in A. mexicana leaves, including berberine and jatrorrhizine, as well as protopine, alocriptopine and sanguinarine [10].

Growth kinetics analysis of T. vaginalis was performed. The doubling time of the parasite was $4.01 \mathrm{hr}$, while exponential growth phase, in which the parasite enters a period characterized by cell duplication and maximum metabolic activity, was reached after $24 \mathrm{hr}$, the maximum slope of the curve will be the specific growth rate of the organism in that particular environment, these culture characteristics are in line with the clinical characteristics and the progress of the natural infection [23]. The times obtained in this study are consistent with those previously reported previously for this same strain [16].

The activities of the AmexS and AmexL extracts were compared by one-way ANOVA, and no significant differences were found in their activities $(P>0.05)$. These results are consistent with the expectations that the chemical components present in both extracts are similar, since the secondary metabolites, such as berberinoids, to which antiparasitic activity has been attributed, are widely distributed in the plant. Subsequently, the percentages of inhibition against T. vaginalis in each of the concentrations evaluated of both extracts were compared, finding a significant difference in the AmexS $(\mathrm{F}=2,233.83$, $P<0.001)$ and AmexL $(F=885.62, P<0.001)$ extracts. In order to compare the percentages of inhibition in each pair of concentrations in both extracts, the Tukey (PostHoc) test was applied. This analysis revealed a significant difference between the different concentrations tested, except in the highest concentrations (i.e. 500 and 1,000 $\mu \mathrm{g} / \mathrm{ml}$ ), the results are shown in Table 2 (different letters show significant differences). These findings confirm that the concentrations had a dose-response 
effect; these concentrations are relevant since the total raw extract is evaluated without fractionation or purification. In 2011, it was found that the aqueous extract of A. mexicana leaves exhibited significant anthelmintic activity against Ascaridia galli and Pheretima posthuma in a dose dependent manner at concentration of $100 \mathrm{mg} / \mathrm{ml}$ [13].

The $\mathrm{IC}_{50}$ values of both the AmexS and AmexL extracts, metronidazole and berberine, were determined. Antiparasitic activity of A. mexicana against different etiological agents has been demonstrated, as for example it has been found that it has effective activity against $P$. falciparum has also been demonstrated, as the aqueous extract of the aerial parts of this plant exhibited an $\mathrm{IC}_{50}$ of $5.9 \mu \mathrm{g} / \mathrm{ml}$ [24]. Activity of the methanolic extract of A. mexicana leaves against E. histolytica trophozoites has been reported, and the results revealed a dose-dependent behavior with lethality percentages of $98.1 \%$ and $75.0 \%$ at concentrations of $500 \mu \mathrm{g} / \mathrm{ml}$ and $125 \mu \mathrm{g} / \mathrm{ml}$, respectively [25]. At the moment there are no reports of the use of extracts of A. mexicana or its fractions against $T$. vaginalis and our results seem even more promising when sub-fractions of the extracts [26] or the majority metabolite are evaluated, as in our case that Berberine showed a greater inhibitory capacity $\left(\mathrm{IC}_{50}=40.7 \mu \mathrm{g} / \mathrm{ml}\right)$ compared to complete extracts analyzed by the Probit test, in which it can be seen that the upper and lower limits are overlapped between AmexS and AmexL, but not with berberine.

Once the trichomonacidal activities of the extracts were determined, the extracts were partially purified by fractionation based on their solubility in five solvents with various polarities. The most efficient fractions were the methanolic partition, AmexL3 classified as an active fraction. Partitioning of a crude extract with solvents of different polarities is common for the extraction of different components because it is possible to extract them and then purify and identify them via chromatographic and spectroscopic techniques. Metabolites derived from berberine with biological activity against the human colon cancer cell line SW480 were identified via extraction and purification from the methanolic A. mexicana extract, among which the chloroformic and methanolic fractions were noteworthy [22]. These berberine derivatives were also shown to have an effect against Plasmodium berghei in a murine model [27]. The present study is relevant because there are no reports of the use of A. mexicana extracts or their fractions against $T$. vaginalis, although studies have evaluated extracts (acetone, methanol, ethanol, and aqueous) of this plant or their frac- tions for potential effects against many etiologic agents as bacteria, fungi, viruses, nematodes and parasites [13].

To characterize the active fraction (AmexL3), it was analyzed via mass spectrometry (Fig. 3). Fragmentation of the ion observed at $336 \mathrm{~m} / \mathrm{z}$, which corresponded to quaternary berberine $\left([\mathrm{M}]^{+}\right)$, ions were observed at $321 \mathrm{~m} / \mathrm{z}\left(\mathrm{M}-\mathrm{CH}_{3}\right), 320 \mathrm{~m} / \mathrm{z}$ $\left(\mathrm{M}-\mathrm{CH}_{4}\right)$, and at 304, 306, and $292 \mathrm{~m} / \mathrm{z}\left(\mathrm{M}-\mathrm{CH}_{4}-\mathrm{CO}\right)$. In turn, fragmentation of the ion observed at $338 \mathrm{~m} / \mathrm{z}$, which was attributed to quaternary jatrorrhizine $\left([\mathrm{M}]^{+}\right)$, generated ions at $323 \mathrm{~m} / \mathrm{z}\left(\mathrm{M}-\mathrm{CH}_{3}\right), 322 \mathrm{~m} / \mathrm{z}\left(\mathrm{M}-\mathrm{CH}_{4}\right), 306 \mathrm{~m} / \mathrm{z}\left(\mathrm{MH}-\mathrm{CH}_{3} \mathrm{O}\right)$, and $294 \mathrm{~m} / \mathrm{z}\left(\mathrm{M}^{+} \mathrm{H}-3 \mathrm{CH}_{3}\right)$. These fragmentation patterns confirm the presence of berberine and jatrorrhizine [28-30].

The alkaloids found in the AmexL3 fraction are perhaps responsible for the biological activity, as their effectiveness has been attributed to their presence in plant extracts evaluated against the parasites G. lamblia, E. histolytica, and even T. vaginalis [31]. It has been reported that berberine has several pharmacological effects and activity against a variety of bacteria, fungi, protozoa, helminths and viruses; furthermore, it has been demonstrated that when berberine is mixed with other alkaloids, it has more robust activity against different microorganisms [20].

It has also been demonstrated that berberine sulfate exerts inhibitory effects against G. lamblia, T. vaginalis and E. histolyti$\mathrm{ca}$ in axenic cultures, in which it was observed that the trophozoites swelled. In addition, the presence of glycogen deposits and the appearance of irregularly shaped vacuoles in the cytoplasm were observed with morphological changes in parasites, including chromatin aggregation in the nucleus, formation of autophagic vacuoles and aggregations of small vacuoles in the cytoplasm were observed [32]. The presence of the jatrorrhizine alkaloid has been reported in plants such as Enantia chlorantha and A. mexicana and, its antimicrobial and antifungal activity has been explored [20]; and it has been shown to be effective against $P$. falciparum, $L$. donovani, and $T$. $b$. rhodesiense in vitro assays [12,14]. Li et al. [33] found that jatrorrhizine derivatives had much stronger antimicrobial effects compared with that of pure jatrorrhizine.

In this context, considering the potential use of the extracts, it was decided to evaluate the cytotoxicity of the crude A. mexicana stem and leaf extracts by a human erythrocyte hemolysis test. Hemolysis assays are usually used to test the toxicity of relatively low concentrations of extracts; for example, it was reported that the methanolic extract of Nymphaea nouchali leaves showed no hemolytic activity at concentrations from 40 to 
$100 \mu \mathrm{g} / \mathrm{ml}$ [19]. In the present study, it was decided to evaluate the toxicity at high concentrations, i.e., 1,000 $\mu \mathrm{g} / \mathrm{ml}$, and with total extracts (AmexS and AmexL) to test the full range of compounds present in the crude extracts. In a similar study [34], assays were performed with the hexane extract of Bridelia ferruginea leaves, and its hemolytic effect was evaluated at concentrations of 20 and $80 \mathrm{ng} / \mathrm{ml}$, which resulted in $4.8 \%$ and $91.7 \%$ hemolysis, respectively. When comparing these results with those obtained in the present study, in which we tested concentrations up to $1,000 \mu \mathrm{g} / \mathrm{ml}$, none of our extracts can be considered to be significantly toxic $(P \leq 0.05$ with approximately $2.5 \%$ hemolysis) based on the criteria of Karimi et al. [35]. These findings indicate that this toxicity could be related to the mechanical stress imparted by the stirring used in the method.

Considering the impact of trichomoniasis on public health and the increasing number of metronidazole resistant isolates, it is important to develop alternatives for treating this infection, new research indicates that when $T$. vaginalis adheres to normal epithelial cells, it causes inflammation, cytotoxicity, production of proinflammatory cytokines, and epithelial-mesenchymal transition (EMT) [36]. Natural products are a promising source of active molecules, and the ethnopharmacological approach retrieves knowledge of medicinal plants held by the population. This ancestral wisdom, in combination with phytochemical and pharmacological studies, is highly valuable for the bioprospecting of safe and accessible medications [37].

This pioneering study showed relevant details of the activity of A. mexicana, a plant traditionally used by the mexican indigenous population to treat infectious diseases. Methanolic extracts of A. mexicana stems and leaves showed inhibitory activity against T. vaginalis growth in vitro, with the leaf extract being the more effective. Neither extract showed hemolytic activity against human erythrocytes. HPLC-MS analysis of the extract fractions with the highest trichomonacidal activity revealed the presence of the berberine alkaloid. These novel findings not only support the anti-parasitic potential of medicinal plants but further strengthen the prospects of exploring plants as promising alternative anti-parasitic agents.

\section{ACKNOWLEDGMENTS}

The authors thank Dr. Gustavo Ponce García and Dr. Roberto Mercado Hernández for their technical assistance. And au- thors thank the financial support of the National Council of Science and Technology (CONACYT) through Project CB176853 and the subsidy received for Joel H. Elizondo Luevano (Registration no. 418935).

\section{CONFLICTS OF INTEREST}

The authors declare that there is no conflict of interest regarding the publication of this paper.

\section{REFRENCES}

1. Kissinger P. Trichomonas vaginalis: a review of epidemiologic, clinical and treatment issues. BMC Infect Dis 2015; 15: 307.

2. Wendel KA, Workowski KA. Trichomoniasis: challenges to Appropriate Management. Clin Infect Dis 2007; 44 (suppl): 123129.

3. Mokdad AH, Forouzanfar MH, Daoud F, El Bcheraoui C, Moradi-Lakeh M, Khalil I, Afshin A, Tuffaha M, Charara R, Barber RM, Wagner J, Cercy K, Kravitz H, Coates MM, Robinson M, Estep K, Steiner C, Jaber S, Mokdad AA, O'Rourke KF, Chew A, Kim P, El Razek MM, Abdalla S, Abd-Allah F, Abraham JP, Abu-Raddad LJ, Abu-Rmeileh NM, Al-Nehmi AA, Akanda AS, Al Ahmadi H, Al Khabouri MJ, Al Lami FH, Al Rayess ZA, Alasfoor D, AlBuhairan FS, Aldhahri SF, Alghnam S, Alhabib S, Al-Hamad N, Ali R, Ali SD, Alkhateeb M, AlMazroa MA, Alomari MA, Al-Raddadi R, Alsharif U, Al-Sheyab N, Alsowaidi S, Al-Thani M, Altirkawi KA, Amare AT, Amini H, Ammar W, Anwari P, Asayesh H, Asghar R, Assabri AM, Assadi R, Bacha U, Badawi A, Bakfalouni T, Basulaiman MO, Bazargan-Hejazi S, Bedi N, Bhakta AR, Bhutta ZA, Bin Abdulhak AA, Boufous S, Bourne RR, Danawi H, Das J, Deribew A, Ding EL, Durrani AM, Elshrek Y, Ibrahim ME, Eshrati B, Esteghamati A, Faghmous IA, Farzadfar F, Feigl AB, Fereshtehnejad SM, Filip I, Fischer F, Gankpé FG, Ginawi I, Gishu MD, Gupta R, Habash RM, Hafezi-Nejad N, Hamadeh RR, Hamdouni H, Hamidi S, Harb HL, Hassanvand MS, Hedayati MT, Heydarpour P, Hsairi M, Husseini A, Jahanmehr N, Jha V, Jonas JB, Karam NE, Kasaeian A, Kassa NA, Kaul A, Khader Y, Khalifa SE, Khan EA, Khan G, Khoja T, Khosravi A, Kinfu Y, Defo BK, Balaji AL, Lunevicius R, Obermeyer CM, Malekzadeh R, Mansourian M, Marcenes W, Farid HM, Mehari A, Mehio-Sibai A, Memish ZA, Mensah GA, Mohammad KA, Nahas Z, Nasher JT, Nawaz H, Nejjari C, Nisar MI, Omer SB, Parsaeian M, Peprah EK, Pervaiz A, Pourmalek F, Qato DM, Qorbani M, Radfar A, Rafay A, Rahimi K, Rahimi-Movaghar V, Rahman SU, Rai RK, Rana SM, Rao SR, Refaat AH, Resnikoff S, Roshandel G, Saade G, Saeedi MY, Sahraian MA, Saleh S, Sanchez-Riera L, Satpathy M, Sepanlou SG, Setegn T, Shaheen A, Shahraz S, Sheikhbahaei S, Shishani K, Sliwa K, Tavakkoli M, Terkawi AS, Uthman OA, Westerman R, Younis MZ, El Sayed Zaki M, Zannad F, Roth GA, Wang H, Naghavi M, Vos T, Al Rabeeah AA, Lopez AD, Murray CJ. Health in times 
of uncertainty in the eastern Mediterranean region, 1990-2013: a systematic analysis for the Global Burden of Disease Study 2013. Lancet Glob Heal 2016; 4: e704-e713.

4. Patel B, Patel P, Patel R. Effect of different extracts from Celosia argentea on calcium and phosphate inhibition in vitro. Int J Pharm Pharm Sci 2011; 3: 337-339.

5. Sharanappa R, Vidyasagar GM. Plant profile, phytochemistry and pharmacology of Argemone Mexicana Linn. A review. Int J Pharm Pharm Sci 2014; 6: 45-53.

6. Sharma A, Flores-Vallejo R del C, Cardoso-Taketa A, Villarreal ML. Antibacterial activities of medicinal plants used in Mexican traditional medicine. J Ethnopharmacol 2017; 208: 264-329.

7. Bhalke RD, Gosavi SA. Anti-stress and antiallergic effect of Argemone mexicana stems in Asthma. Arch Pharm Sci Res 2009; 1: 127-129.

8. Chang YC, Chang FR, Khalil AT, Hsieh PW, Wu YC. Cytotoxic benzophenanthridine and benzylisoquinoline alkaloids from Argemone mexicana. Z Naturforsch C J Biosci 2003; 58: 521-526.

9. Magos-guerrero GA, Santiago-mejía J, Carrasco OF. Exploratory studies of some Mexican medicinal plants: cardiovascular effects in rats with and without hypertension. J Intercult Ethnopharmacol 2013; 3: 274-279.

10. Sharma BD, Malhotra S, Bhatia V, Rathee M. Epidemic dropsy in India. Postgrad Med J 1999; 75: 657-661.

11. Rubio-Pina J, Vazquez-Flota F. Pharmaceutical applications of the benzylisoquinoline alkaloids from Argemone mexicana L. Curr Top Med Chem 2013; 13: 2200-2207.

12. Willcox ML, Graz B, Falquet J, Sidibé O, Forster M, Diallo D. Argemone mexicana decoction for the treatment of uncomplicated falciparum malaria. Trans R Soc Trop Med Hyg 2007; 101: 11901198.

13. Brahmachari G, Gorai D, Roy R. Argemone mexicana: chemical and pharmacological aspects. Rev bras farmacogn 2013; 23: 559575.

14. Malebo HM, Wenzler T, Cal M, Swaleh SM, Omolo MO, Hassanali A, Séquin U, Häussinger D, Dalsgaard P, Hamburger M, Brun R, Ndiege IO. Anti-protozoal activity of aporphine and protoberberine alkaloids from Annickia kummeriae (Engl. \& Diels) Setten \& Maas (Annonaceae). BMC Complement Altern Med 2013; 13: 48.

15. Harborne JB. Phytochemical Methods. A Guide to Modern Techniques of Plant analysis. 3rd ed. London, UK. Chapman and Hall. 1998, pp 54-84.

16. Mata-Cárdenas BD, Vargas-Villarreal J, González-Salazar F, Palacios-Corona R, Said-Fernández S. A new vial microassay to screen antiprotozoal drugs. Pharmacologyonline 2008; 1: 529537.

17. Ntie-Kang F, Onguéné PA, Lifongo LL, Ndom JC, Sippl W, Mbaze LM. The potential of anti-malarial compounds derived from African medicinal plants, part II: a pharmacological evaluation of non-alkaloids and non-terpenoids. Malar J 2014; 13: 81.

18. Kumar G, Karthik L, Bhaskara Rao KV. Hemolytic activity of Indian medicinal plants towards human erythrocytes: an in vitro study. Elixir Appl Botany 2011; 40: 5534-5537.

19. Lakshmi G, Smitha N, Ammu SV, Priya CL, Bhaskara Rao KV. Phytochemical profile, in vitro antioxidant and hemolytic activities of various leaf extract of Nymphaea Nouchali Linn: an in vitro study. Int J Pharm Pharm Sci 2014; 6: 548-552.

20. Singh S, Singh TD, Singh VP, Pandey VB. A new benzylisoquinoline alkaloid from Argemone mexicana. Nat Prod Res 2010; 24: 63-67.

21. Trujillo-Villanueva K, Rubio-Piña J, Monforte-González M, Ramírez-Benítez E, Vázquez-Flota F. The sequential exposure to jasmonate, salicylic acid and yeast extract promotes sanguinarine accumulation in Argemone mexicana cell cultures. Biotechnol Lett 2012; 34: 379-385.

22. Singh S, Verma M, Malhotra M, Prakash S, Singh TD. Cytotoxicity of alkaloids isolated from Argemone mexicana on SW480 human colon cancer cell line. Pharm Biol 2016; 54: 740-745.

23. Kostara I, Carageorgiou H, Varonos D, Tzannetis S. Growth and survival of Trichomonas vaginalis. J Med Microbiol 1998; 47: 555560.

24. Schrader FC, Barho M, Steiner I, Ortmann R, Schlitzer M. The antimalarial pipeline - an update. Int J Med Microbiol 2012; 302: 165-171.

25. Elizondo-Luévano JH, Castro-Ríos R, Sánchez-García E, Hernández-García ME, Vargas-Villarreal J, Rodríguez-Luis OE, ChávezMontes A. In vitro study of antiamoebic activity of methanol extracts of Argemone mexicana on trophozoites of Entamoeba histolytica HM1-IMSS. Can J Infect Dis Med Microbiol 2018; 2018: 7453787.

26. Raghav D, Ashraf SM, Mohan L, Rathinasamy K. Berberine induces toxicity in HeLa cells through perturbation of microtubule polymerization by binding to tubulin at a unique site. Biochemistry 2017; 56: 2594-2611.

27. Simoes-pires C, Hostettmann K, Haouala A, Cuendet M, Falquet J, Graz B, Christen P. Reverse pharmacology for developing an anti-malarial phytomedicine. The example of Argemone mexicana. Int J Parasitol Drugs Drug Resist 2014; 4: 338-346.

28. Grycová L, Dostál J, Marek R. Quaternary protoberberine alkaloids. Phytochemistry 2007; 68: 150-175.

29. Liu F, Li Z, Shi X, Zhong M. Determination of berberine, palmatine and jatrorrhizine in rabbit plasma by liquid chromatography-electrospray ionization-mass spectrometry. J Pharm Biomed Anal 2011; 56: 1006-1015.

30. Tang DQ, Zheng XX, Chen X, Yang DZ, Du Q. Quantitative and qualitative analysis of common peaks in chemical fingerprint of Yuanhu Zhitong tablet by HPLC-DAD-MS/MS. J Pharm Anal 2014; 4: 96-106.

31. Birdsall TC, Kelly GS. Therapeutic potential of an alkaloid found in several medicinal plants. Altern Med Rev 1997; 2: 94-103.

32. Kaneda $Y$, Torii $M$, Tanaka T, Aikawa M. In vitro effects of berberine sulphate on the growth and structure of Entamoeba histolytica, Giardia lamblia and Trichomonas vaginalis. Ann Trop Med Parasitol 1991; 85: 417-425.

33. Li Y, Wang H, Si N, Ren W, Han L, Xin S, Zuo R, Wei X, Yang J, 
Zhao H, Bian B. Metabolic profiling analysis of berberine, palmatine, jatrorrhizine, coptisine and epiberberine in zebrafish by ultra-high performance liquid chromatography coupled with LTQ Orbitrap mass spectrometer. Xenobiotica 2015; 45: 302311.

34. Vinjamuri S, Shanker D, Ramesh R, Nagarajan S. In vitro evaluation of hemolytic activity and cell viability assay of hexanoic extracts of Bridelia ferruginea Benth. World J Pharm Pharm Sci 2015; 4: 1263-1268.

35. Karimi G, Aghasizadeh M, Razavi M, Taghiabadi E. Protective effects of aqueous and ethanolic extracts of Nigella sativa L. and
Portulaca oleracea L. on free radical induced hemolysis of RBCs. Daru 2011; 19: 295-300.

36. Kim JH, Han IH, Kim SS, Park SJ, Min DY, Ahn MH, Ryu JS. Interaction between Trichomonas vaginalis and the prostate epithelium. Korean J Parasitol 2017; 55: 213-218.

37. Ávila-Blanco ME, Rodríguez MG, Moreno Duque JL, MuñozOrtega M, Ventura-Juárez J. Amoebicidal activity of essential oil of Dysphania ambrosioides (L.) Mosyakin \& Clemants in an amoebic liver abscess hamster model. Evid Based Complement Alternat Med 2014; 2014: 1-7. 
